\title{
COST-EFFECTIVENESS ANALYSIS OF CEFTRIAXONE GENERIC AND PATENT IN CHILDREN WITH TYPHOID
}

\author{
SANTI PURNA SARI ${ }^{*}$, ICUT DIKI ADESTIA PUTRI ${ }^{1}$, BINAR NURSANTI $^{2}$ \\ ${ }^{1}$ Faculty of Pharmacy, Clinical Pharmacy Laboratory, Universitas Indonesia, Depok, 16424, Indonesia, ${ }^{2}$ Department of Financial, Karya \\ Bhakti Pratiwi Hospital, Bogor, 16880, Indonesia. Email: santisari@farmasi.ui.ac.id \\ Received: 29 June 2018, Revised: 27 September 2018, Accepted: 25 October 2018
}

\begin{abstract}
Objective: This study aimed to measure and compare the effectivity and cost of the two types of ceftriaxone to determine the more cost-effective treatment.

Methods: In a cross-sectional analytical study, prescription and administrative financial data were retrospectively collected using the total sampling method. Data of 63 patients, comprising 43 and 20 patients treated with generic and patent ceftriaxone, respectively, were analyzed. The effectiveness of the treatment was measured in terms of the length of hospital stay of the patients. The total cost of the treatment was the total median of the costs of drugs, laboratory examinations, medical device usage, physician service, and hospitalization.
\end{abstract}

Results: The effectiveness of both generic and patent ceftriaxone was 4 days of hospital stay. Cost-effectiveness ratio of generic ceftriaxone was Rp $575,937.25 /$ day and that of patent ceftriaxone was $\mathrm{Rp} 888,601.75 /$ day.

Conclusion: Generic ceftriaxone was more cost-effective than patent ceftriaxone.

Keywords: Cost-effectiveness analysis, Pharmacoeconomic, Typhoid fever, Ceftriaxone, Karya Bhakti Pratiwi Hospital.

(C) 2018 The Authors. Published by Innovare Academic Sciences Pvt Ltd. This is an open access article under the CC BY license (http://creativecommons. org/licenses/by/4. 0/) DOI: http://dx.doi.org/10.22159/ijap.2018.v10s1.16

\section{INTRODUCTION}

Typhoid fever is a communicable disease accounting for 22 million cases annually and is the cause of mortality in $216,000-600,000$ people worldwide. Typhoid fever is an endemic disease in Indonesia [1]. The aim of prescribing antibiotics is to cease the bacterial growth and shorten the duration of signs and symptoms of the disease. The selection of antibiotics is based on sensitivity pattern in each hospital [2]. In Karya Bhakti Pratiwi Hospital, generic and branded antibiotics have been used as the first-line treatment for pediatric patients with typhoid fever since 2012. Based on the СРОВ manuals, generic and branded medicines should have equal effectivity. However, the effectivity of generic and branded medicines remains different, as reported in a previous study [3]. This probability of a significant cost difference as well as effectivity difference between generic and branded medicines encouraged us to perform a pharmacoeconomic analysis of these medicines using cost-effectiveness analysis (CEA). In this study, CEA was used to measure and compare the effectiveness and cost between these two types of treatments to identify the more costeffective treatment.

\section{METHODS}

In this cross-sectional analytical study, secondary of prescription and cost administrative data of patients were retrospectively obtained [4]. The study was conducted at the inpatient installation of Karya Bhakti Pratiwi Hospital, Bogor, from February to April 2017. The study included all children with typhoid fever who were administered generic or patent ceftriaxone in 2016 and who met the inclusion criteria. Data were obtained using the total sampling method. Variables measured included medication effectivity, total medication cost, age, and sex.

Inclusion criteria were children with typhoid fever aged 1-19 years who were treated with generic or patent ceftriaxone. Exclusion criteria were patients with unclear, incomplete, or untracked medical records, those undergoing treatment with antibiotics other than ceftriaxone, and those with a change of treatment class or antibiotic type during the inpatient period.

Data were analyzed using Microsoft Excel and IBM Statistical Package for the Social Sciences 20.0., Armonk, NY: IBM Corp. with a confidence interval of $95 \%$ and an $\alpha=0.05$. The calculation of effectivity and medication cost included the effectivity proportion of medications including the length of hospital stay and total medication cost in rupiah in each group of generic and patent ceftriaxone.

Total medication cost was obtained from the total cost of direct medical components including drugs, medical device use, laboratory examinations, and service in each group of generic and patent ceftriaxone.

After obtaining total medication cost, CEA was performed, which comprised cost-effectiveness ratio (CER), cost-effectiveness incremental ratio (CEIR), and sensitivity analysis. CER was obtained by comparing total medication cost on medication effectiveness (only in patients free of nausea and vomiting).

\section{$\mathrm{CER}=\frac{\text { Totalof medication cost }}{\text { Effectiveness(clinicla outcomes) }}$}

CEIR was obtained by comparing total incremental medication cost with incremental effectiveness between the two ceftriaxone groups. The value obtained considered CEIR score, which represented the additional cost in changing from one alternative drug to another.

CEIR $=\frac{\text { Drug cost } A-D r u g \operatorname{cost} B}{\text { Drugeffect } A-\text { Drug effect } B}$

Two types of one-way sensitivity analyses were used in this study: Using simulated increase and decrease in total medication cost and using 
maximum and minimum simulations from total medication cost. Both sensitivity analyses were performed with a fixed effectiveness value.

\section{RESULTS}

Based on prescription data in 2016, 167 pediatric patients used generic or patent ceftriaxone as treatment for typhoid fever in 2016. After adjusting the inclusion and exclusion criteria, the study included 63 children. Patients' characteristics are summarized in Table 1.

\section{CEA}

Treatment effectiveness in this study was measured in terms of the length of hospital stay of patients. The results of effectiveness analysis parameter were presented as the median length of stay of the generic and patent ceftriaxone groups. Based on the analysis, the median length of hospital stay was 4 days. Mann-Whitney U-test revealed no significant difference between generic and patent ceftriaxone treatment effectiveness in terms of the length of hospital stay $(p=0.548)$.

The results of cost analysis using the total cost of direct medical components for the two groups are presented in Table 2.

Drug cost was defined as the cost of ceftriaxone used during the hospitalization period. The median drug cost of generic and patent ceftriaxone was Rp 97,000 and Rp 1,070,880, respectively. Based on non-parametric Mann-Whitney U-test, the p-value obtained was 0.000 . Drug costs of generic and patent ceftriaxone were significantly different $(\mathrm{p}<0.05)$.
Laboratory examinations were performed in the diagnostic stage, therapy progress observation, and final results of the treatment. Laboratory examinations for pediatric patients with typhoid fever usually include the Widal test, immunochromatography test, and polymerase chain reaction test (3.1 [EN] Please expand the abbreviation). Median laboratory examination cost during the use of ceftriaxone was calculated and compared between the generic and patent ceftriaxone groups. Based on the sample data obtained from Information System and Management of Hospital, median laboratory costs for the two groups were Rp 308,000 and Rp 365,000, respectively. Based on non-parametric Mann-Whitney U-test, the p-value obtained was 0.963 ( $p>0.05)$, indicating that laboratory examination cost was not significantly different between the two groups.

Median medical device use cost during the use of ceftriaxone was calculated and compared between the generic and patent ceftriaxone groups. Medical devices included needle, syringe, infusion equipment, $\mathrm{NaCl}$ 0.9\% solution, alcohol swab, bandage, mask, and gloves. Based on cost data stated on Information System of Hospital in each patient, median medical device use cost in the generic and patent ceftriaxone

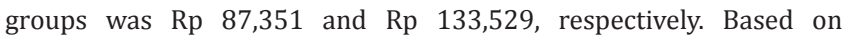
nonparametric Mann-Whitney U-test, the p-value obtained was 0.040 $(\mathrm{p}<0.05)$, indicating that medical device use cost was significantly different between the two groups.

Service cost included physician service cost during patients' stay in the hospital. Median service cost in generic and patent ceftriaxone groups was $\operatorname{Rp} 130,000$ and $\operatorname{Rp~260,000,~respectively.~Based~on~non-parametric~}$

Table 1: Patient characteristics

\begin{tabular}{|c|c|c|c|}
\hline Patient characteristics & $\begin{array}{l}\text { Total } \\
n=63(\%)\end{array}$ & $\begin{array}{l}\text { Generic ceftriaxone } \\
n=43(\%)\end{array}$ & $\begin{array}{l}\text { Patient ceftriaxone } \\
n=20(\%)\end{array}$ \\
\hline \multicolumn{4}{|l|}{ Age } \\
\hline Toddlers $(0-5$ years $)$ & $35(55.55)$ & $22(51.16)$ & $13(65)$ \\
\hline Children $(>5-11$ years $)$ & 25 (39.69) & $18(41.87)$ & $7(35)$ \\
\hline Adolescents (>11-19 years) & $3(4.76)$ & $3(6.97)$ & $0(0)$ \\
\hline Total & $63(100)$ & $43(100)$ & $20(100)$ \\
\hline \multicolumn{4}{|l|}{ Sex } \\
\hline Female & $35(55.55)$ & $25(58.14)$ & $10(50)$ \\
\hline Total & $63(100)$ & $43(100)$ & $20(100)$ \\
\hline \multicolumn{4}{|l|}{ Payment source } \\
\hline Self-found & $24(38.1)$ & $13(30.23)$ & $11(55)$ \\
\hline BPJS (National Health Insurance) & $24(38.1)$ & $22(51.16)$ & $2(20)$ \\
\hline Private Health Insurance & $15(23.8)$ & $8(18.61)$ & $7(35)$ \\
\hline Total & $63(100)$ & $43(100)$ & $20(100)$ \\
\hline \multicolumn{4}{|l|}{ Treatment class } \\
\hline Class III & $23(36.50)$ & $15(34.88)$ & $8(40)$ \\
\hline First Class & $3(4.76)$ & $1(2.32)$ & $2(10)$ \\
\hline VIP Class & $11(17.49)$ & $5(11.65)$ & $6(30)$ \\
\hline VVIP Class & $1(1.58)$ & $1(2.32)$ & $0(0)$ \\
\hline Total & $63(100)$ & $43(100)$ & $20(100)$ \\
\hline \multicolumn{4}{|l|}{ Length of hospital stay } \\
\hline Median (days) & 4 & 4 & 4 \\
\hline Range & $3-7$ & $3-7$ & $3-7$ \\
\hline
\end{tabular}

Table 2: Comparison of medical cost between generic and patent ceftriaxone groups

\begin{tabular}{lll}
\hline Cost Type & $\begin{array}{l}\text { Generic } \\
\text { ceftriaxone (Rp) }\end{array}$ & \multicolumn{1}{c}{$\begin{array}{c}\text { Patent } \\
\text { ceftriaxone (Rp) }\end{array}$} \\
\hline Median drug cost & 97,000 & $1,070,880$ \\
Median laboratory cost & 308,000 & 365,000 \\
Median medical device use cost & 87,351 & 133,529 \\
Median service cost & 130,000 & 260,000 \\
Median hospitalization cost & $1,555,000$ & $1,695,000$ \\
Median total medication cost & $2,303,749$ & $3,554,407$ \\
\hline
\end{tabular}

*significant difference 
Mann-Whitney U-test, the p-value obtained was 0.153 (p>0.05), indicating that service cost was not significantly different between the two groups.

Median hospitalization cost in the generic and patent ceftriaxone

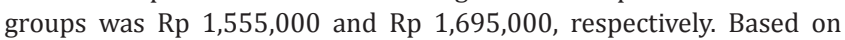
non-parametric Mann-Whitney U-test, the p-value obtained was 0.170 ( $p>0.05$ ), indicating that hospitalization was not significantly different between the two groups.

Median total medication cost for patent ceftriaxone (Rp 3,554,407) was higher than that for generic ceftriaxone (Rp 2,303,749). Based on non-parametric Mann-Whitney U-test, the p-value obtained was $0.000(\mathrm{p}<0.05)$, indicating that total medication cost was significantly different between the two groups. Median total medication cost for each medication was used further in CEA, which consisted of CER, CEIR, and sensitivity analysis.

CER

Mean CER was calculated by comparing median total medication cost with medication effectiveness in generic and patent ceftriaxone groups. Based on normality test, total cost data distribution was not normal; hence, median total medication cost used in the calculation was considered total medication cost. Medication effectiveness was defined as median length of hospital stay. The CER of each medication group is shown in Table 3 .

CER of the generic ceftriaxone group was lower (Rp 575,937.25/ day) than that of the patent ceftriaxone group (Rp 888,601.75/day). Moreover, CER was calculated according to the treatment class of patients. CER of each medication group based on their treatment class is shown in Table 4.

The length of hospital stay in the generic and patent ceftriaxone groups was similar, showing effectiveness equality between the two

Table 3: CER

\begin{tabular}{llll}
\hline $\begin{array}{l}\text { Ceftriaxone } \\
\text { type }\end{array}$ & $\begin{array}{l}\text { Total medication } \\
\text { Cost (Rp) }\end{array}$ & $\begin{array}{l}\text { Length of } \\
\text { hospital stay }\end{array}$ & CER (Rp/day) \\
\hline Generic & Rp 2,303,749 & 4 & $575,937.25$ \\
Patent & Rp 3,554,407 & 4 & $888,601.75$ \\
\hline
\end{tabular}

CER: Cost-effectiveness ratio medication groups. However, total medication cost in the generic ceftriaxone group was lower than that in the patent group; hence, generic ceftriaxone was in a dominant position in the effectiveness and cost table (Table 5). Meanwhile, the patent ceftriaxone group was in the dominant position. A clear position between the medication groups showed that generic ceftriaxone was more cost-effective than patent ceftriaxone; hence, calculation of the CEIR was not necessary. Subsequently, a sensitivity analysis was performed to measure uncertainty from various data used as well as resulting from the pharmacoeconomic analysis.

\section{Sensitivity analysis}

Sensitivity analysis was performed by simulating $25 \%$ or $50 \%$ increase and decrease in median total medication cost. The results of the sensitivity analysis are shown in Table 6.

The results of the sensitivity analysis showed that even though median total medication cost from generic ceftriaxone was decreased by $25 \%$ and $50 \%$ or increasing by $25 \%$ and $50 \%$, CER of the generic ceftriaxone group remained lower than that of the baseline CER of the patent ceftriaxone group (Rp 888,601.8). Meanwhile, a significant difference in the CER of the patent ceftriaxone was observed only at $50 \%$ decrease median total medication cost, at which point the CER of the patent ceftriaxone group $(\mathrm{Rp} 444,300.88)$ became lower than the baseline CER of the generic ceftriaxone group (Rp 575,937.3).

\section{DISCUSSION}

Of the 63 patients in this study, 43 and 20 patients were administered generic or patent ceftriaxone of a brand, respectively. The analysis was performed by comparing total medicinal cost and treatment effectiveness of the generic and patent ceftriaxone groups.

Among the patients who met the inclusion criteria, the number of patients using generic ceftriaxone $(71.67 \%)$ was more than that of patients using patent ceftriaxone (28.33\%). This might be explained by the fact that a majority of patients were covered under BPJS health insurance (National Health Insurance), and the use of generic ceftriaxone was recommended according to BPJS terms and conditions in 2014 stated in National Formularies based on Keputusan Menkes RI No.328/Menkes/SK/2013 [5].

Based on the payment source type, 24 patients paid total medication cost independently (38.09\%); 24 patients paid total medication cost

Table 4: CER according to treatment class

\begin{tabular}{lllll}
\hline Ceftriaxone type & Treatment class & Total medication cost (Rp) & Length of stay & $\begin{array}{l}\text { CER } \\
\text { (Rp/day) }\end{array}$ \\
& & & & $744,804.5$ \\
Generic & Class I & $2,979,218$ & 4 & $401,228.25$ \\
& Class II & $1,604,913$ & 4 & 422,749 \\
& Class III & $1,690,996$ & 4 & $855,747.25$ \\
& First Class & $3,422,989$ & 4 & $1,058,551.25$ \\
& VIP Class & $4,234,205$ & 4 & $1,175,807.25$ \\
Patent & VVIP Class & $4,703,229$ & $4,151,926.25$ \\
& Class I & $4,607,705$ & 4 & $821,620.89$ \\
& Class II & $3,697,294$ & 4.5 & $760,027.75$ \\
& Class III & $3,040,111$ & 4 & $1,172,686.75$ \\
& First Class & $4,690,747$ & 4 & $1,475,471.63$ \\
\hline
\end{tabular}

CER: Cost-effectiveness ratio

Table 5: Effectiveness and cost of generic and patent ceftriaxone use for pediatric patients with typhoid fever

\begin{tabular}{|c|c|c|c|}
\hline Effectiveness and cost & Lower cost & Same cost & Higher cost \\
\hline Lower effectiveness & (Need CEIR calculation) & & Patent to generic ceftriaxone in Class II+(Domined) \\
\hline Same effectiveness & Overall generic to patent ceftriaxone+(Dominant) & & Overall patent to generic ceftriaxone+(Domine) \\
\hline Higher effectiveness & Generic to patent ceftriaxone in Class II+(Dominant) & & (Need CEIR calculation) \\
\hline
\end{tabular}

CEIR: Cost-effectiveness incremental ratio 
Table 6: One-way sensitivity analysis with simulation of increase and decrease in median total medication cost

\begin{tabular}{|c|c|c|c|}
\hline Strategy & $\begin{array}{l}\text { Median total medication } \\
\text { cost (Rp) }\end{array}$ & $\begin{array}{l}\text { Length of hospital } \\
\text { stay (days) }\end{array}$ & $\begin{array}{l}\text { CER } \\
\text { (Rp/day) }\end{array}$ \\
\hline \multicolumn{4}{|l|}{ Generic ceftriaxone } \\
\hline$\%$ decrease in median total medication cost & $2,303,749$ & 4 & $575,937.3$ \\
\hline $25 \%$ decrease in median total medication cost & $1,727,812$ & 4 & $431,952.9$ \\
\hline $50 \%$ decrease in median total medication cost & $1,151,875$ & 4 & $287,968.6$ \\
\hline $25 \%$ increase in median of total medication cost & $2,879,686$ & 4 & $719,921,6$ \\
\hline $50 \%$ increase in median total medication cost & $3,455,624$ & 4 & $863,905.9$ \\
\hline Decrease of $0 \%$ from the median of total medication cost & $3,554,407$ & 4 & $888,601.8$ \\
\hline Decrease of $25 \%$ from the median of total medication cost & $2,665,805$ & 4 & $666,451.31$ \\
\hline Decrease of $50 \%$ from the median of total medication cost & $1,777,204$ & 4 & $444,300.88$ \\
\hline Increase of $25 \%$ from the median of total medication cost & $4,443,009$ & 4 & $1,110,752.19$ \\
\hline Increase of $50 \%$ from the median of total medication cost & $5,331,611$ & 4 & $1,332,902.63$ \\
\hline
\end{tabular}

using BPJS (38.09\%), with 3 using BPJS COB, 20 using BPJS non-PBI, and one patient using BPJS PBI, and 15 patients (23.81\%) paid total medicinal cost using other insurance. Patients with BPJS PBI had the right to avail treatment Class III. Meanwhile, patients with BPJS nonBPI and BPJS CPB had the right to avail treatment Class I, II, or III depending on the premise paid. Patients with BPJS non-PBI and COB could propose to change for a better treatment class by paying the cost difference outside the BPJS premise. Based on hospital policy, patients hospitalized with insurance were referred to treatment Classes I, II, first class, VIP, and VVIP. However, room selection was based on patients' need and desire. This caused the variable distribution of treatment classes in pediatric patients with typhoid fever in this study.

Karya Bhakti Pratiwi Hospital provides five types of treatment classes for inpatients: Class I, Class II, Class III, first class, VIP class, and VVIP class. Based on the treatment class type, of the 43 patients with typhoid fever who were administered generic ceftriaxone, 11 were in Class I (25.58\%), 10 were in Class II (23.25\%), 15 were in Class III (34.88\%), 1 was in first class (2.32\%), 5 were in VIP class $(11.65 \%)$, and 1 was in VVIP class (2.32\%). Meanwhile, of the 20 patients with typhoid fever who were administered patent ceftriaxone, two were in Class I $(10.00 \%)$, two were in Class II (10\%), eight were in Class III $(40.00 \%)$, three were in first class $(15.00 \%)$, and four were in VIP class $(20.00 \%)$. Treatment cost for each class was different, which affected total medication cost.

The length of hospital stay was defined as the total number of days from the day patients was hospitalized until discharge from the hospital. Median length of hospital stay in patients who were administered generic or patent ceftriaxone was 4 days, ranging from 3 to 7 days.

Treatment effectiveness was measured in terms of the length of hospital stay. There was no significant difference between the ceftriaxone types used and treatment effectiveness in terms of the length of hospital stay. The results of effectiveness analyses were in agreement with the government policy stating that quality, efficacy, and safety should not be different between generic and branded drugs as well as patent drugs with the same active substance [6].

Analysis of CER of the generic and patent ceftriaxone groups based on treatment class showed that CER of the generic ceftriaxone group was lower than that of the patent ceftriaxone in all treatment classes. However, CER calculation alone was not adequate to identify the more cost-effective group [7-10]. Medication alternative position in effectiveness and cost table was determined to confirm the effectiveness and cost of the medications. In effectiveness and cost analysis, the cost was the medication cost and not the mean of effectiveness and cost.

Pharmacoeconomic analysis was performed to account for uncertainty from all obtained and used data. To calculate uncertainty, the cause of uncertainty was identified, scored, and interpreted with sensitivity analysis. On the basis of the results of sensitivity analysis, it can be concluded that before and after cost simulations, CER of the generic ceftriaxone group was lower than that of the patent ceftriaxone group, except when median total medicinal cost of patent ceftriaxone was decreased by $50 \%$. This study is suggested to be taken as evaluation consideration for the regulator so that generic ceftriaxone can be taken as it is more cost-effective than branded ceftriaxone. However, further study is needed and if it possible, to consider other effectivity parameters such as number of anti-salmonella immunoglobulin $\mathrm{M}$ counted, number of decreased fever temperature, and the count of leukocytes. It is also suggested to consider including indirect cost and intangible cost in further study.

\section{CONCLUSION}

The medication effectiveness of generic ceftriaxone was equal to that of patent ceftriaxone, as evident by the equal median length of hospital stay (4 days) for both drug types. Statistically, there was no significant difference in medication effectiveness between generic and patent ceftriaxone in terms of the length of hospital stay ( $p=0.548)$. Median total medication cost of patent ceftriaxone was higher (Rp $3,554,407)$ than that of generic ceftriaxone ( $R p 2,303,749)$, and there was a statistically significant difference in medication effectiveness between generic and patent ceftriaxone in terms of median total medication cost $(p=0.000)$. Based on CEA, generic ceftriaxone (CER: Rp 575,937.25/day) was more cost-effective than patent ceftriaxone (CER: Rp 888,601.75/day).

\section{CONFLICTS OF INTEREST}

The authors declare that they have no conflicts of interest.

\section{REFERENCES}

1. WHO. Guidelines for the Management of Typhoid Fever. Harare: WHO; 2011

2. Indonesian Ministry of Health. Indonesian Health Insurance Organization revival momentum of pharmacoeconomics. Jakarta: Indonesian Ministry of Health; 2014. Available from: http://www. binfar.kemkes.go.id/2014/06/bpjs-kesehatan-momentum-kebangkitanfarmako-ekonomi/\#.WLJeef4e3YE. [Last accessed on 2018 Jan 05]

3. Virginia N. Cost-Effectiveness Analysis of Generic Ondansetron with Logos and Trademarks on Breast Cancer Patients with Moderate Emetogenic Chemotherapy at Dharmais Cancer Hospital in 2012. Depok: Universitas Indonesia; 2010.

4. Sudigdo. Basics of Clinical Research Methods. Jakarta: Binarupa Aksara; 2010

5. Indonesian Ministry of Health. Guidelines for Implementing Pharmacoeconomic Studies. Jakarta: Indonesian Ministry of Health; 2013.

6. Indonesian Ministry of Health. Systematics Guidelines for Controlling Typhoid Fever. Jakarta: Indonesian Ministry of Health; 2013.

7. Trask LS. Pharmacoeconomics: Principles, methods, and applications. 
In: Pharmacotherapy: A Patophysiologic Approach. $8^{\text {th }}$ ed. New York (NY): The McGraw-Hill Companies, Inc.; 2011. p. 1-3.

8. Kurian A, Aswini V, Shiva RB, Jerry DM, Rama P, Vinoth V. A study on antimicrobial sensitivity and cost analysis of antibiotics in pediatric unit at a tertiary care hospital. Asian J Pharm Clin Res 2018;11:242-51.
9. Nimin P, Santhosh KV. A comparative study on drug use of antimicrobial agents in medical and surgical intensive care units of a tertiary care hospital. Asian J Pharm Clin Res 2018;11:310-3.

10. Miraci M, Haloci E, Toto B. The evaluation of rational use of some drugs in Albania. Asian J Pharm Clin Res 2015;8:90-4. 